Carl Llor ${ }^{1,2}$

Ana Moragas ${ }^{3}$

Josep M. Cots $^{4}$

\section{Implementation of the delayed antibiotic prescribing strategy. Prospective observation study in primary care}

\author{
'University Institute in Primary Care Research Jordi Gol, Via Roma Health Centre, Barcelona, Spain \\ ${ }^{2}$ Department of Public Health, General Practice. University of Southern Denmark, Odense, Denmark. \\ ${ }^{3}$ Universitat Rovira i Virgili. Jaume I Health Centre, Tarragona, Spain. \\ ${ }^{4}$ Primary Healthcare Centre La Marina, Barcelona, Spain.
}

Article history

Received: 30 September 2021; Revision Requested: 21 October 2021; Revision Received: 24 October 2021; Accepted: 26 November 2021; Published: 3 February 2022

\section{ABSTRACT}

Objectives. We aimed to compare the actual consumption of antibiotics among patients issued delayed antibiotic prescribing with the consumption observed in a non-systematic review of studies on delayed prescribing.

Methods. Observational study carried out in three primary care centres from September 2018 until March 2020. We tracked the electronic records of the 82 patients with episodes of acute bronchitis and 44 acute pharyngitis who were given a patient-led delayed prescription to determine whether the prescription was filled and when this medication was obtained.

Results. The prescriptions were never filled in 50 cases $(39.7 \%)$, but five patients took another antibiotic within the first two weeks. Out of 76 patients who did take the delayed prescription, only 12 obtained the medication based on the instructions given by the doctors (15.8\%).

Conclusions. The strategy of delayed antibiotic prescribing resulted in a reduction in antibiotic use, but this reduction was lower than in randomised clinical trials, being comparable to the results obtained with other observational studies on delayed antibiotic prescribing. In addition, only a few patients adhered to the doctors' instructions.

Keywords: Antimicrobial Stewardship; Primary Health Care; Antibacterial Agents.
Implementación de la estrategia de prescripción diferida de antibióticos. Estudio observacional prospectivo en atención primaria

\section{RESUMEN}

Objetivos. Evaluar el consumo de antibióticos entre los pacientes a los que se les efectuó una prescripción antibiótica diferida y compararlo con el consumo observado en una revisión no sistemática de estudios de prescripción diferida.

Métodos. Estudio observacional en tres centros de salud desde septiembre 2018 hasta marzo 2020. Se realizó un seguimiento de los registros electrónicos de los 82 pacientes con episodios de bronquitis aguda y 44 faringitis aguda a los que se les entregó una prescripción diferida para evaluar si fue a la farmacia a buscarla y cuándo la obtuvo.

Resultados. No fueron a buscar la medicación en 50 casos $(39,7 \%)$, pero cinco pacientes tomaron otro antibiótico en las dos primeras semanas. De los 76 pacientes que recogieron la prescripción, solo 12 la obtuvieron según las instrucciones de sus médicos (15,8\%).

Conclusiones. La estrategia de prescripción diferida reduce el consumo de antibióticos, pero esta reducción es menor que la que se observa en ensayos clínicos, siendo comparable con los resultados observados en otros estudios observacionales sobre prescripción diferida. Además, solo unos pocos pacientes siguieron las instrucciones de sus médicos.

Palabras clave: Administración de antimicrobianos; Atención Primaria; Agentes antibacterianos.

\section{INTRODUCTION}

General practitioners (GP) prescribing antibiotics for acute Correspondence: Carl Llor

University Institute in Primary Care Research Jordi Gol, Via Roma Health Centre, Barcelona Gran Via de les Corts Catalanes, 497, atic - 08007 Barcelona

E-mail: carles.llor@gmail.com respiratory tract infections (RTI) are usually aware that the prescription is inappropriate but are often influenced in their decision by the perception that patients expect an antibiotic. This 
conflict may also make GPs feel uncomfortable with the decision of whether to prescribe. Delayed prescribing could potentially address the patient's expectation of an antibiotic prescription, but also the GP's clinical uncertainty, while minimising actual antibiotic consumption. To put it briefly, a GP offers an antibiotic prescription, but asks the patient to wait for no spontaneous improvement before deciding whether to obtain the antibiotic at the community pharmacy. A recent individual patient data meta-analysis showed that this strategy is a safe and effective strategy for most patients, including those in higher risk subgroups and is associated with similar symptom duration as no antibiotic prescribing and is unlikely to lead to a worse symptom control than immediate antibiotic prescribing [1].

A 2017 systematic Cochrane Collaboration review, including randomised clinical trials (RCT), found that delayed antibiotic prescriptions were associated with significantly decreased antibiotic use as 31\% of the cases admitted to taking the antibiotic [2]. However, the actual use of antibiotics in current practice might be higher than that reported in clinical trials. We assessed whether patients given a delayed prescription filled it or not, and if so, how many days after the index consultation was the antibiotic obtained, and we compared our results with a non-systematic review of studies on delayed antibiotic prescribing aimed at evaluating the actual consumption of antibiotics differentiating RCTs and observational studies.

\section{METHODS}

Patients were recruited from 6 general practices in three urban primary care centres in Catalonia, Spain. All the participating GPs were familiar with the delayed prescribing technique and routinely employed it in their practice. Eligible subjects were those of any age presenting with a sore throat with two Centor criteria, or uncomplicated acute bronchitis, defined as cough without chest signs in patients without lung comorbidity, as recommended by the updated version of the National Institute for Health and Clinical Excellence guideline (NICE) on RTI [3], who were visited in the different consultations from September 2018 until March 2020. We decided to stop recruiting patients at that moment because of the onset of the COVID-19 pandemic.

The recruiting doctor issued an antibiotic prescription during the consultation but advised the patient to use it after three days in the case of sore throat and after seven days for episodes of acute bronchitis and only in the absence of spontaneous improvement as suggested by the NICE guideline [3]. Patients were also given the sheet recommended by the Plan Nacional de Resistencia a los Antibióticos (PRAN) of the Spanish Agency of Medicines and Health Products (Supplementary material - Appendix 1). Patients were informed about their participation in a study on rationalising antibiotic treatment, but they were not aware of the real objective in an attempt not to influence their behaviour (Supplementary material Appendix 2). Participating GPs registered whether the patients filled the prescription given and tracked the information collected in the electronic records within the first two weeks after the index consultation. In case patients collected the antibiotic they were called by the same GPs to make sure when they at-

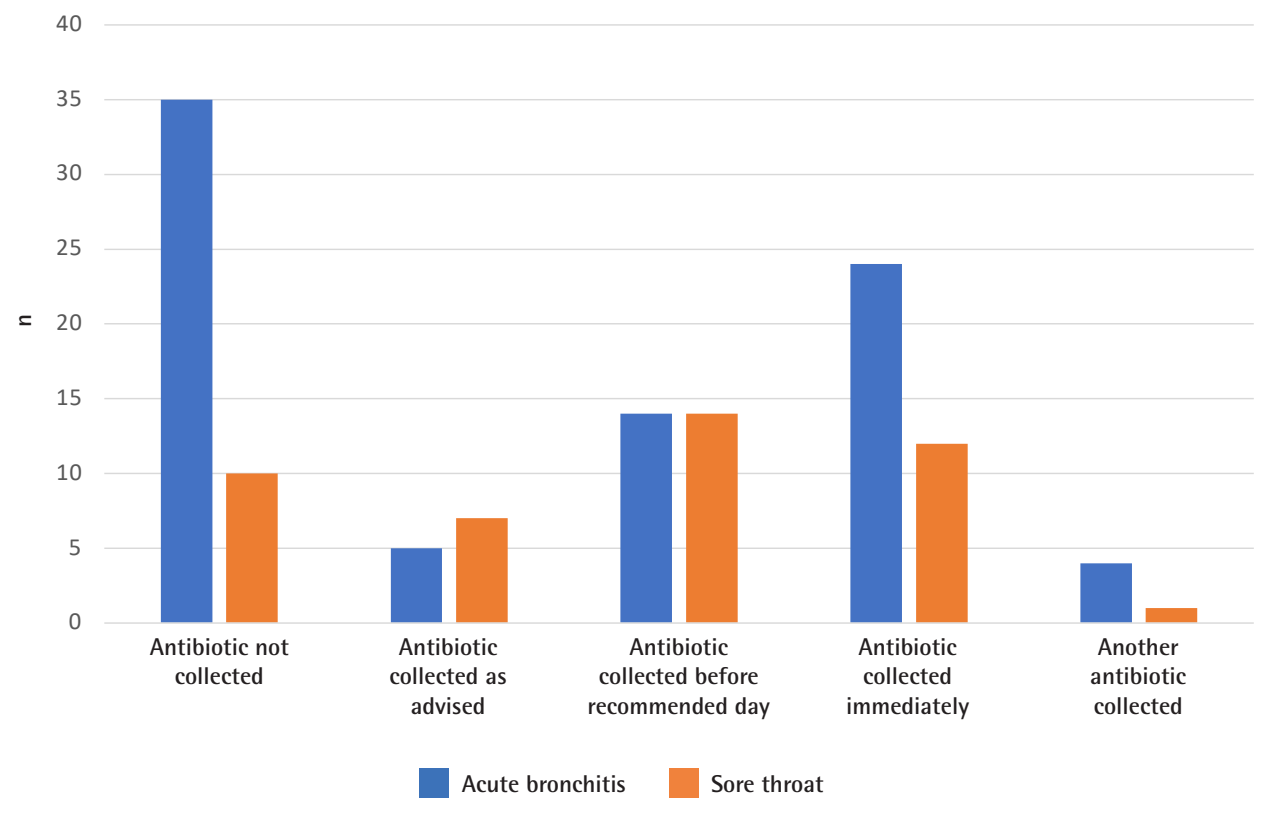

\begin{tabular}{l|l} 
Figure 1 & Distribution of patients with RTls and their attitude about the delayed
\end{tabular} antibiotic prescribing given. 


\begin{tabular}{|c|c|c|c|c|c|c|c|c|c|}
\hline Tabla 1 & $\begin{array}{l}\text { Antibiotic } \\
\text { observatio }\end{array}$ & $\begin{array}{l}\text { consumption c } \\
\text { onal studies. }\end{array}$ & obser & ved with the d & elayed antibio & tic strategy ir & n randomised clinic & cal trials an & nd prospective \\
\hline \multirow[t]{2}{*}{ Study } & \multirow[t]{2}{*}{ Country } & \multirow[t]{2}{*}{ Setting } & \multirow{2}{*}{$\begin{array}{l}\text { Sample } \\
\text { size }\end{array}$} & \multirow[t]{2}{*}{ Population } & \multirow[t]{2}{*}{ Condition } & \multicolumn{3}{|c|}{ Number of patients who declared consuming the antibiotic $(\%)$} & \multirow[t]{2}{*}{ Observations } \\
\hline & & & & & & $\begin{array}{l}\text { Immediate } \\
\text { antibiotic }\end{array}$ & Delayed antibiotic & No antibiotic & \\
\hline \multicolumn{10}{|l|}{ Randomised clinical trials } \\
\hline Little, 1997 [4] & UK & Primary care & 716 & Children and adults & Sore throat & $210 / 211(99.5)$ & $55 / 176(31.2)$ & $23 / 184(12.5)$ & Collection \\
\hline Dowell, 2001 [5] & UK & Primary care & 191 & Adults & Cough & $92 / 92(100)$ & $43 / 95(45.3)$ & - & Collection \\
\hline Little, 2001 [6] & UK & Primary care & 315 & Children & Acute otitis media & $132 / 151(87.4)$ & $36 / 150(24.0)$ & - & Collection \\
\hline Arroll, 2002 [7] & New Zealand & Primary care & 129 & Adults & Common cold & $55 / 67(85.1)$ & $32 / 67(47.8)$ & - & Patient led \\
\hline McCormick, 2005 [8] & USA & Paediatric clinic & 223 & Children & Acute otitis media & $109 / 109(100)$ & 38/108 (35.2) & - & Collection \\
\hline Little, 2005 [9] & UK & Primary care & 807 & Children and adults & Lower RTI & 185/193 (95.9) & 39/197 (19.8) & 29/182 (15.1) & Collection \\
\hline Spiro, 2006 [10] & USA & $\begin{array}{l}\text { Emergency } \\
\text { department }\end{array}$ & 283 & Children & Acute otitis media & 116/133 (87.2) & 50/132 (37.9) & - & Patient led \\
\hline Chao, 2008 [11] & USA & $\begin{array}{l}\text { Paediatric emergency } \\
\text { department }\end{array}$ & 232 & Children & Acute otitis media & - & 40/106 (37.7) & $13 / 100(13.0)$ & Patient led \\
\hline Little, 2014 [12] & UK & Primary care & 889 & Children and adults & Acute RTI & - & $\begin{array}{l}\text { Recontact 34/92 (37.0); } \\
\text { postdated 37/101 (36.6); } \\
\text { collection 28/85 (39.2); } \\
\text { patient-led 35/89 (39.3) }\end{array}$ & 26/99 (26.3) & $\begin{array}{l}\text { Recontact, postdated, } \\
\text { collection, patient led }\end{array}$ \\
\hline De La Poza, 2016 [13] & Spain & Primary care & 405 & Adults & Acute RTI & $46 / 51(90.2)$ & $\begin{array}{l}\text { Patient-led 32/98 (32.7); } \\
\text { collection 23/100 (23.0) }\end{array}$ & $6 / 49(12.2)$ & $\begin{array}{l}\text { Patient led and } \\
\text { collection }\end{array}$ \\
\hline Mas-Dalmau, 2021 [14] & Spain & Primary care & 437 & Children & Acute RTI & $142 / 148(95.9)$ & $37 / 146(25.3)$ & $17 / 142(12.0)$ & Patient led \\
\hline TOTAL & & & & & & $1,087 / 1,155(94.1)$ & $\begin{array}{l}\text { Collection 252/911 (27.7); } \\
\text { patient-led 216/638 (33.9) }\end{array}$ & $116 / 756(15.3)$ & \\
\hline \multicolumn{10}{|c|}{ Prospective observational studies } \\
\hline Edwards, 2003 [15] & UK & Primary care & 327 & Children and adults & Acute RTI & - & $136 / 256$ (53.1) & - & Patient-led \\
\hline Siegel, 2003 [16] & USA & Paediatric clinic & 194 & Children & Acute otitis media & NR & $55 / 175(31.4)$ & - & Collection \\
\hline Marchetti, 2005 [17] & Italy & Primary care & 1,672 & Children & Acute otitis media & NR & $383 / 1099$ (34.8) & - & Not reported \\
\hline Fischer, 2009 [18] & USA & $\begin{array}{l}\text { Emergency } \\
\text { department }\end{array}$ & 144 & Children & Acute otitis media & NR & 105/144 (72.9) & - & Patient-led \\
\hline Høye, 2011 [19] & Norway & Primary care & 304 & Children and adults & Acute RTls & - & $141 / 304(46.4)$ & - & Patient-led \\
\hline Francis, 2012 [20] & 13 areas & Primary care & 2,690 & Adults & Cough or lower RTI & $924 / 1,292(71.5)$ & $93 / 169(55.0)$ & NR & Patient led \\
\hline Little, 2017 [21] & UK & Primary care & 28,856 & Adults & Acute lower RTI & NR & NR & NR & Patient led \\
\hline Moore, 2017 [22] & UK & Primary care & 12,626 & Adults & Sore throat & NR & $115 / 197(58.4)$ & NR & Patient led \\
\hline TOTAL & & & & & & $924 / 1,292(71.5)$ & $\begin{array}{l}\text { Collection 55/175 (31.4); } \\
\text { patient-led 600/1070 (56.1) }\end{array}$ & - & \\
\hline
\end{tabular}

Collection: collection of the prescription at the primary health centre; NR: this information is not reported in the paper; Patient-led: the patient is given the prescription the same day of the consultation; Postdated: the patient is given the prescription signed with a future date; Recontact: recontact the doctor again for a prescription; RTI: respiratory tract infection

tended the pharmacy to fill up the prescription. The study was approved by the Research Ethics Committee IDIAP Jordi Gol (reference number, 16/093).

\section{RESULTS}

A total of 126 patients were given a delayed antibiotic prescription, of which 82 cases corresponded to acute bronchitis.
The mean age was 41.2 (SD 10.6) with 72 women (57.1\%). The prescriptions were never obtained in 50 cases (39.7\%). However, five patients admitted taking another antibiotic within the first two weeks after the index consultation. Therefore, a total of 81 patients obtained an antibiotic for that episode in the 2-week follow-up period (64.3\%). Out of 76 patients who did obtain the delayed prescription, 36 declared to have filled the medication the same day of the visit $(47.4 \%)$. As described in 
Figure 1, only 12 patients obtained the medication based on the instructions given by the doctors (15.8\%).

\section{DISCUSSION}

In this observational study of adults presenting with sore throat and acute bronchitis, the strategy of the delayed antibiotic prescribing results in a reduction in antibiotic use, but this reduction is not as high as the percentage observed in RCTs. In addition, only a small percentage of patients obtaining the medication adhered to the doctors' instructions.

Despite not asking about the actual consumption of antibiotics, $64.3 \%$ of the patients filled the delayed prescription at the pharmacy or declared taking another antibiotic. This result is not different from the actual consumption of antibiotics observed in the different studies on delayed antibiotic consumption carried out in observational studies. As shown in table 1, the actual antibiotic consumption among patients assigned to different types of delayed prescribing ranged from $19.8 \%$ to $47.8 \%$ in the different RCTs published to date [4-14] and from 31.4\% to $72.9 \%$ in observational studies [15-22]. Observational studies better reflect daily practice. In RCTs of delayed prescribing GPs are usually instructed to use the approach as part of a full recommendation that includes advice about the limited effectiveness and disadvantages of using antibiotics for an infectious condition and advice about the likely time course of their symptoms and how to decide when to take the antibiotic. Symptoms of RTIs usually take longer than patients expect, and therefore advice about how long to delay the prescription is an important element of this recommendation. Inappropriate provision of advice is a possible reason for the difference in the reported consumption found in RCTs of this approach and in this study. The method of delivering the delayed prescription to the patient may also influence how delayed prescriptions are used. As shown in table 1 consumption of delayed antibiotics is lower if it is left up to the patients to collect the prescription at a later point rather than being given to the patient during the consultation. The results of our study are not dissimilar to those of observational studies using the same approach. In a study carried out in 13 European countries, in which 55\% of the 169 participants, who provided data about the antibiotic consumption when a delayed antibiotic prescribing was offered, consumed an antibiotic during the study period [20]. In this study, 30\% started taking their delayed antibiotics on the day that they were prescribed [20].

This study has several limitations. We cannot ensure that all the patients who filled the prescription had taken the medication, which is the most important limitation of this study. We recruited only 126 patients as the study described routine care in only a few primary care centres. Nonetheless, we do not consider that the results would have been much different if we had recruited more patients. Participants agreed to participate in a study on rationalising antibiotic therapy and this could have affected their behaviour; however, they were not informed about its real objective. Patients were not randomised; however, data on routine prescribing behaviour in everyday clinical practice can only be obtained through observational data as in our study.
Qualitative studies carried out in Spain report that some patients feel uncomfortable about being given the decision about when to use antibiotics and others report taking 'delayed' antibiotics immediately, as also suggested in our study. Some clinicians think that the strategy helps empower patients, provides reassurance, and helps to meet their expectations, but others expressed concerns about patients using them inappropriately, about masking serious illness, and about medicolegal problems [23]. Apart from giving this information sheet, GPs should be trained about the duration of delay and provide advice regarding the limited effectiveness of antibiotics, their disadvantages, and when to consider using these drugs. Otherwise, poor clinician adherence is likely to undermine the effectiveness of the strategy. Opinion leaders may be able to play a role in increasing awareness about the need for clear communication as part of any delayed prescribing strategy. It is obvious that the delayed strategy is only valid in some cases. If doctors think that an antibiotic therapy is not warranted, a delayed antibiotic strategy should not be used unless there is clear and voiced antibiotic demand for therapy by patients [24]. A 'no antibiotic strategy' is always preferable to a delayed antibiotic prescribing strategy. If delayed prescribing is offered, a clear explanation is needed about the advice to be given to patients about when to use their prescription (symptoms not resolved, not getting better, getting worse) and about safety netting (when to reconsult). If this is not voiced during the consultation, we might create confusion by sending mixed messages to patients such as 'an antibiotic is not needed, but here is an antibiotic'.

In conclusion, the strategy of delayed antibiotic prescribing is associated with a lower antibiotic consumption, but this reduction is lower than expected and only a few patients adhered to the doctors' instructions. Although this strategy could be valid in some cases doctors should prefer a no antibiotic strategy and deprescribing antibiotic courses already initiated if they no longer consider they are appropriate.

\section{ACKNOWLEDGMENTS}

To the doctors and the patients who participated in this study.

\section{FUNDING}

None to declare

\section{CONFLICTS OF INTEREST}

$\mathrm{CL}$ reports receiving research grants from Abbott Diagnostics. The other authors declare no competing interests.

\section{REFERENCES}

1. Stuart B, Hounkpatin H, Becque T, Yao G, Zhu S, Alonso-Coello P, et al. Delayed antibiotic prescribing for respiratory tract infections: 
individual patient data meta-analysis. BMJ. 2021;373:n808. doi: 10.1136/bmj.n808.

2. Spurling GK, Del Mar CB, Dooley L, Foxlee R, Farley R. Delayed antibiotic prescriptions for respiratory infections. Cochrane Database Syst Rev. 2017;9:CD004417. doi: 10.1002/14651858.CD004417. pub5.

3. National Institute for Health and Clinical Excellence. Prescribing of antibiotics for self-limiting respiratory tract infections in adults and children in primary care. Clinical guideline 69, 2008 (NICE, London).

4. Little P, Williamson I, Warner G, Gould C, Gantley M, Kinmonthet AL. Open randomised trial of prescribing strategies in managing sore throat. BMJ. 1997;314:722-7. doi: 10.1136/bmj.314.7082.722.

5. Dowell J, Pitkethly M, Bain J, Martin S. A randomised controlled trial of delayed antibiotic prescribing as a strategy for managing uncomplicated respiratory tract infection in primary care. $\mathrm{Br} J$ Gen Pract. 2001;51:200-5.

6. Little P, Gould C, Williamson I, Moore M, Warner G, Dunleavey J. Pragmatic randomised controlled trial of two prescribing strategies for childhood acute otitis media. BMJ. 2001;322:336-42. doi: 10.1136/bmj.322.7282.336.

7. Arroll B, Kenealy T, Kerse N. Do delayed prescriptions reduce the use of antibiotics for the common cold? A single-blind controlled trial. J Fam Pract. 2002;51:324-8.

8. McCormick DP, Chonmaitree T, Pittman C, Saeed K, Friedman NR, Uchida T, et al. Non severe acute otitis media: a clinical trial comparing outcomes of watchful waiting versus immediate antibiotic treatment. Pediatrics. 2005;115:1455-65. doi: 10.1542/peds.20041665.

9. Little P, Rumsby K, Kelly J, Watson L, Moore M, Warner G, et al. Information leaflet and antibiotic prescribing strategies for acute lower respiratory tract infection: a randomized controlled trial. JAMA. 2005;293:3029-35. doi: 10.1001/jama.293.24.3029.

10. Spiro DM, Tay KY, Arnold DH, Dziura JD, Baker MD, Shapiro ED. Wait-and-see prescription for the treatment of acute otitis media: a randomized controlled trial. JAMA. 2006;296:1235-41. doi: 10.1001/jama.296.10.1235.

11. Chao JH, Kunkov $\mathrm{S}$, Reyes LB, Lichten $\mathrm{S}$, Crain EF. Comparison of two approaches to observation therapy for acute otitis media in the emergency department. Pediatrics. 2008;121:e1352-6. doi: 10.1542/peds.2007-2278.

12. Little P, Moore M, Kelly J, Williamson I, Leydon G, McDermott L, et al. PIPS Investigators. Delayed antibiotic prescribing strategies for respiratory tract infections in primary care: pragmatic, factorial, randomised controlled trial. BMJ. 2014;348:g1606. doi: 10.1136/ bmj.g1606.

13. de la Poza Abad M, Mas Dalmau G, Moreno Bakedano M, et al. Delayed Antibiotic Prescription (DAP) Group. Prescription strategies in acute uncomplicated respiratory infections: a randomized clinical trial. JAMA Intern Med. 2016;176:21-9. doi: 10.1001/jamainternmed.2015.7088.

14. Mas-Dalmau G, Villanueva López C, Gorrotxategi Gorrotxategi $P$, Argüelles Prendes E, Espinazo Ramos 0, Valls Duran T, et al. DAP Pediatrics Group. Delayed antibiotic prescription for chil- dren with respiratory infections: A randomized trial. Pediatrics. 2021;147:e20201323. doi: 10.1542/peds.2020-1323.

15. Edwards M, Dennison J, Sedgwick P. Patients' responses to delayed antibiotic prescription for acute upper respiratory tract infections. Br J Gen Pract. 2003;53:845-850.

16. Siegel RM, Kiely $M$, Bien JP, Joseph EC, Davis JB, Mendelet $S G$, al. Treatment of otitis media with observation and a safety-net antibiotic prescription. Pediatrics. 2003;112:527-31. doi: 10.1542/ peds.112.3.527.

17. Marchetti F, Ronfani L, Nibali SC, Tamburlini G, Italian Study Group on Acute Otitis Media. Delayed prescription may reduce the use of antibiotics for acute otitis media: a prospective observational study in primary care. Arch Pediatr Adolesc Med. 2005;159:679-84. doi: 10.1097/PEC.0b013e3181b91ffo.

18. Fischer $T$, Singer AJ, Chale S. Observation option for acute otitis media in the emergency department. Pediatr Emerg Care. 2009;25:575-8. doi: 10.1097/PEC.0b013e3181b91ffo.

19. Høye $\mathrm{S}$, Frich JC, Lindbæk M. Use and feasibility of delayed prescribing for respiratory tract infections: a questionnaire survey. BMC Fam Pract. 2011;12:34. doi: 10.1186/1471-2296-12-34.

20. Francis NA, Gillespie D, Nuttall J, Hood K, Little P, Verheij T, et al. Delayed antibiotic prescribing and associated antibiotic consumption in adults with acute cough. Br J Gen Pract. 2012;62:e639-46. doi: 10.3399/bjgp12X653561.

21. Little $P$, Stuart B, Smith $S$, Thompson MJ, Knox K, van den Bruel $A$, et al. Antibiotic prescription strategies and adverse outcome for uncomplicated lower respiratory tract infections: prospective cough complication cohort (3C) study. BMJ. 2017;357:j2148. doi: 10.1136/bmj.j2148.

22. Moore M, Stuart $B$, Hobbs FDR, Butler CC, Hay AD, Campbell J, et al; on behalf of the DESCARTE investigators. Symptom response to antibiotic prescribing strategies in acute sore throat in adults: the DESCARTE prospective cohort study in UK general practice. Br J Gen Pract. 2017;67:e634-e42. doi: 10.3399/bjgp17X692321.

23. de la Poza Abad M, Mas Dalmau G, Gich Saladich I, Martínez García L, Llor C, Alonso-Coello P. Use of delayed antibiotic prescription in primary care: a cross-sectional study. BMC Fam Pract. 2019;20:45. doi: 10.1186/s12875-019-0934-7.

24. Rowe TA, Linder JA. Delayed antibiotic prescriptions in ambulatory care. Reconsidering a problematic practice. JAMA. 2020;323:177980. doi: 10.1001/jama.2020.2325. 